\title{
Effect of Storm Surges and Wind Waves on Morphodynamic Processes in the Bakalskaya Spit Region
}

\author{
L.V. Kharitonova, E.V. Ivancha, D.V. Alekseev \\ Marine Hydrophysical Institute, Russian Academy of Sciences, Sevastopol, \\ Russian Federation \\ e-mail: dalexeev@rambler.ru
}

\begin{abstract}
The effect of changing of wind wave directions and heights as well as storm surge heights on the erosion and accumulation processes in the Bakalskaya Spit region of the Black Sea is studied. Numerical model XBeach (eXtreme Beach behavior) is used. The model includes the interacting blocks for calculating short wind waves, barotropic currents and sediment dynamics. It is shown that the XBeach model reproduces basic characteristics of the Bakalskaya Spit dynamics obtained from the observational data analysis. These characteristics include: spit head displacement in the northwest direction due to erosion of its western part and sediment accumulation near its northeastern part; spit erosion in the area of the isthmus which connects the main part of the spit with its distal part up to its separation. Dependence of the erosion location and spatial dimensions, and sediment accumulation upon the characteristics of waves and surges are obtained. It is revealed that when surges are absent, erosion of the spit isthmus is the strongest in case of the wave running from the west as compared to the cases of the wave running from the southwest and northwest. The seabed erosion of different intensity takes place along the entire coastline of the spit. Sediment is accumulated seawards off the erosion areas, but not continuously along the coast. The areas of the most significant sediment accumulation are located to the east off the spit head and to the southwest from the scour along the spit eastern coast. Presence of surges can result both in increase or decrease of the erosion process depending on the wave direction. Changes of the wave heights produce less impact on the morphodynamic process than those of the surge heights.
\end{abstract}

Keywords: wind waves, wave currents, sediments, numerical simulation.

DOI: 10.22449/1573-160X-2015-1-73-84

(c) 2015, L.V. Kharitonova, E.V. Ivancha, D.V. Alekseev

(C) 2015, Physical Oceanography

Introduction. The Karkinitsky Bay of the Black Sea due to its morphological features $(10-35 \mathrm{~m}$ depths, sandy and muddy bottom structure with the addition of shell limestone, the presence of islands and spits) is an area of intense morphodynamic processes. The Bakalskaya Spit which juts out into the Karkinitsky Bay at $8 \mathrm{~km}$ distance is characterized by special dynamic activity. The width of the spit western branch is $30-80 \mathrm{~m}$, of the eastern branch - $1200-$ $2000 \mathrm{~m}$ [1]. A narrow underwater sandbank (Bakalskaya Bank) extends at up to $40 \mathrm{~km}$ distance to the North. The depths above its peak reach $3.5-4 \mathrm{~m}$.

According to [2], the main morphodynamic processes in the area of Bakalskaya Spit are the following: the erosion of the spit western coast; the extension of its distal part into the Karkinitsy Bay water area in the north-east direction; reduction of the spit width in the area of the isthmus, which connects the main part of the spit with its distal part; separation of distal part from the main part of the spit. After the storms which took place in autumn, 2010 the isthmus was eroded and has not recovered yet, and the distal part of the spit became an island.

The dynamics of sediments in the Bakalskaya Spit region depends on wind waves and sea level oscillations [1], which should be reasonably taken into account during the numerical simulation. However, the setting of these parameters based on the field data or numerical calculations always contain some uncertainty [3]. So the estimation of the dependence of morphodynamic process simulation results in the Bakalskaya Spit region on the variations of wind wave parameters and the sea level 
is of interest. In this work such estimations are carried out on the basis of XBeach (eXtreme Beach behavior) [4] numerical hydrodynamic model.

Mathematical statement of the problem and solution method. XBeach model includes the interacting blocks on the calculation of short wind waves, barotropic currents and sediment dynamics. Short waves in the model are described by non-stationary equation of wave energy balance in the spectral form [4]. An angular distribution of wave spectrum is considered and one peak frequency is used, that is corresponded to the assumption of narrow-band spectrum in the frequency space. The equation of wave energy balance has the following form

$$
\frac{\partial A}{\partial t}+\frac{\partial\left(c_{x} A\right)}{\partial x}+\frac{\partial\left(c_{y} A\right)}{\partial y}+\frac{\partial\left(c_{\theta} A\right)}{\partial \theta}=-\frac{D_{w}}{\sigma},
$$

where $t$ is time; $x$ and $y$ are horizontal coordinates; $A=E_{w} / \sigma$ is wave action density; $E_{w}$ is wave energy; $\sigma$ is eigen wave frequency; $\theta$ is direction of wave propagation; $D_{w}$ is energy dissipation rate due to the wave breaking; $c_{x}, c_{y}$ and $c_{\theta}-$ velocities of energy transfer in the direction of $x, y$ and $\theta$ axes. The second and the third terms in the equation (1) describe energy transfer along the coordinate axes $x$, $y$, and the fourth term describes the effects of wave refraction on the bottom inhomogeneities and currents.

To describe the energy transfer from breaking waves to the rollers the equation of roller energy $E_{r}$ balance is used [5]:

$$
\frac{\partial E_{r}}{\partial t}+\frac{\partial\left(c_{x} E_{r}\right)}{\partial x}+\frac{\partial\left(c_{y} E_{r}\right)}{\partial y}+\frac{\partial\left(c_{\theta} E_{r}\right)}{\partial \theta}=D_{w}-D_{r} .
$$

Here the energy source is $D_{w}$, and $D_{r}$ is a dissipation rate of rollers.

The currents induced by short waves are described by non-linear shallow water equations

$$
\begin{gathered}
\frac{\partial u}{\partial t}+u \frac{\partial u}{\partial x}+v \frac{\partial u}{\partial y}-f v+g \frac{\partial \eta}{\partial x}-\mu\left(\frac{\partial^{2} u}{\partial x^{2}}+\frac{\partial^{2} u}{\partial y^{2}}\right)=\frac{F_{x}-\tau_{b x}}{\rho h}, \\
\frac{\partial v}{\partial t}+u \frac{\partial v}{\partial x}+v \frac{\partial v}{\partial y}+f u+g \frac{\partial \eta}{\partial y}-\mu\left(\frac{\partial^{2} v}{\partial x^{2}}+\frac{\partial^{2} v}{\partial y^{2}}\right)=\frac{F_{y}-\tau_{b y}}{\rho h}, \\
\frac{\partial \eta}{\partial t}+\frac{\partial(h u)}{\partial x}+\frac{\partial(h v)}{\partial y}=0,
\end{gathered}
$$

where $\eta$ is elevation of level; $u, v$ are current velocity components; $f$ is the Coriolis parameter; $g$ is acceleration of gravity; $\mu$ is turbulent viscosity coefficient; $\rho$ is water density; $h$ is dynamic depth; $\tau_{b x}, \tau_{b y}$ are components of bed shear friction stresses which are squarely dependent on the velocities of currents; $F_{x}, F_{y}$ are components of wave-induced additional momentum. These values have the following form:

$$
F_{x}=-\frac{\partial\left(S_{x x}+R_{x x}\right)}{\partial x}-\frac{\partial\left(S_{x y}+R_{x y}\right)}{\partial y}, \quad F_{y}=-\frac{\partial\left(S_{x y}+R_{x y}\right)}{\partial x}-\frac{\partial\left(S_{y y}+R_{y y}\right)}{\partial y} .
$$


In the formulas (6) $S_{i j}$ and $R_{i j}(i, j=x, y)$ are stresses due to the presence of waves and rollers, respectively, and depending on $E_{w}$ and $E_{r}$.

In XBeach model the flows of sediments are determined by expressions [5]

$$
Q_{x}=h C u-\mu_{c} h \frac{\partial C}{\partial x}, \quad Q_{y}=h C v-\mu_{c} h \frac{\partial C}{\partial y},
$$

here $C$ is a depth-averaged concentration of sediments; $\mu_{c}$ is turbulent diffusion coefficient. Changes of $C$ are described by advection-diffusion equation of the following form

$$
\frac{\partial(h C)}{\partial t}+\frac{\partial Q_{x}}{\partial x}+\frac{\partial Q_{y}}{\partial y}=h \frac{C_{e q}-C}{T_{e q}},
$$

where $C_{e q}$ is an equilibrium concentration; $T_{e q}$ is adaptation time of concentration to the equilibrium state. Further, using the known $Q_{x}$ and $Q_{y}$ values the bed deformations are calculated from the equation [5]

$$
(1-p) \frac{\partial z_{b}}{\partial t}+\frac{\partial q_{x}}{\partial x}+\frac{\partial q_{y}}{\partial y}=0,
$$

where $q_{x}=Q_{x}+\alpha|u| \frac{\partial z_{b}}{\partial x} ; q_{y}=Q_{y}+\alpha|v| \frac{\partial z_{b}}{\partial y} ; z_{b}$ is bed surface coordinate; $p$ is soil porosity; $\alpha=1-10$ is setup parameter.

Solving the equation (1) it is assumed that at the rigid lateral boundaries $E_{w}=0$. By the angular variable $E_{w}(\theta=0)=E_{w}(\theta=2 \pi)$ periodicity condition is used, by the frequency variable for minimum $\sigma_{\min }$ and maximum $\sigma_{\max }$ frequencies $-E_{w}\left(\sigma_{\min }\right)=E_{w}\left(\sigma_{\max }\right)=0$ condition is used. In XBeach model for the specifying of boundary conditions at the seaward boundary a 2-D frequencyangular spectrum of the following form is used:

$$
E_{w}(\sigma, \theta)=F(\sigma) \psi(l) \cos ^{2 l}\left(\frac{\theta-\bar{\theta}}{2}\right), \quad \psi(l)=\frac{2^{2 l-1}}{\pi} \frac{\Gamma^{2}(l+1)}{\Gamma(2 l+1)},
$$

where $l$ is index of angular wave dissipation; $\Gamma$ is gamma function; $F(\sigma)$ is JONSWAP (Joint North Sea Wave Project) frequency spectrum calculated by the following formula:

$$
F(\sigma)=0.307 \alpha_{F} \frac{h_{s}}{\sigma_{p}} \frac{\exp \left(-1.23 a^{-4}\right)}{a^{5}} \gamma^{\beta},
$$

where $a=\sigma / \sigma_{p} ; \quad \beta=\exp \left(-\frac{(a-1)^{2}}{2 b}\right) ; \quad b=\left\{\begin{array}{l}0.07 \text { at } a \leq 1 \\ 0.09 \text { at } a>1\end{array} ; \quad h_{s}\right.$ is significant wave height; $\sigma_{p}$ is wave frequency corresponding to the spectral peak ( $\tau_{p}=2 \pi / \sigma_{p}$ is spectra peak period); $\gamma$ is spectral peakedness parameter; $\alpha_{F}=0.0131$ is generalized Phillips parameter.

In the shallow water equations (3) - (5) and in the sediment transport equation (8) the absence of fluid flows and sediment ones at rigid lateral boundaries is PHYSICAL OCEANOGRAPHY NO. 1 (2015) 
assumed. At the open boundaries a condition of weak reflection based on the Method of Characteristics [4] is assumed.

In the XBeach model for difference approximation of (1)-(9) equations a rectangular staggered grid is used. Depth, level, sediment concentration, wave and roller energy are determined in cell centers, and current velocity components, sediment flows and right parts of (3) and (4) equations are determined in the middle of lateral boundaries. The integration is performed on the basis of explicit scheme with an automatic time step selection. In the difference scheme, utilized in the XBeach model, a drying/flooding algorithm is implemented [4].

Input parameters. Digital model of the studied region relief is developed on the basis of the Karkinitsky Bay 1:200 000 scale navigation chart and the data obtained as a result of Marine Hydrophysical Institute expeditions in July, 2007. During the expedition on July 21 a bathymetric observation of Bakalskaya Spit coastal zone from a small vessel was performed. Coastline contour and cross section profiles of spit isthmus and head were obtained during the expedition on July, 27 - 28 according to high-precision GPS-observation data (Fig. 1, a). The analysis of cross section profiles across the main part of the spit showed that beach excess over the sea level in the area of the isthmus (which separates the head from the main part of the spit) is up to $0.9 \mathrm{~m}$.

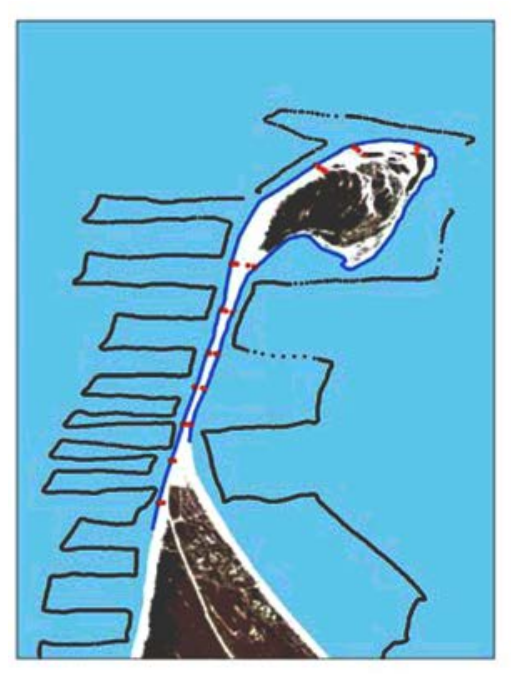

$a$

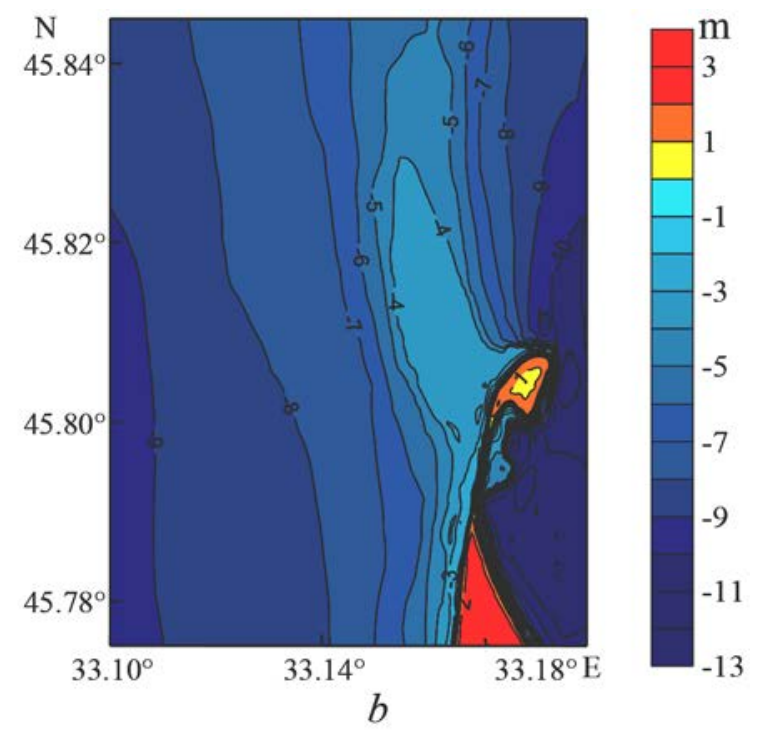

$b$

Fig. 1. Observation work diagram in Bakalskaya Spit region in July, 2007 (black points - depth measurements, red points - cross section profiles across the main part of the spit, blue line - coastline measured contour) (a) and also a schematic map of computational domain land and seabed relief (m) (b)

The seabed relief of computational domain, which covers the northern part of Bakalskaya Spit and Bakalskaya bank and has $2.2 \times 2.9 \mathrm{~km}$ dimensions, is represented in Fig 1, $b$. Grid steps for $x$ and $y$ axes are 17 and $19 \mathrm{~m}$, respectively. Inasmuch as Bakalskaya Spit is a sandy formation [1], we will assume that the spit and the seabed near it consist of medium sand with $D_{50}=5 \cdot 10^{-4}$ particle size and $2650 \mathrm{~kg} / \mathrm{m}^{3}$ density [6]. 
Analysis of numerical experiment results. It is known [7] that morphodynamic processes in the sea coastal zone are mainly affected by wind waves and wave currents (caused by wind waves). The direction of wave propagation and wave intensity are determined by wind effect and also by shoreline

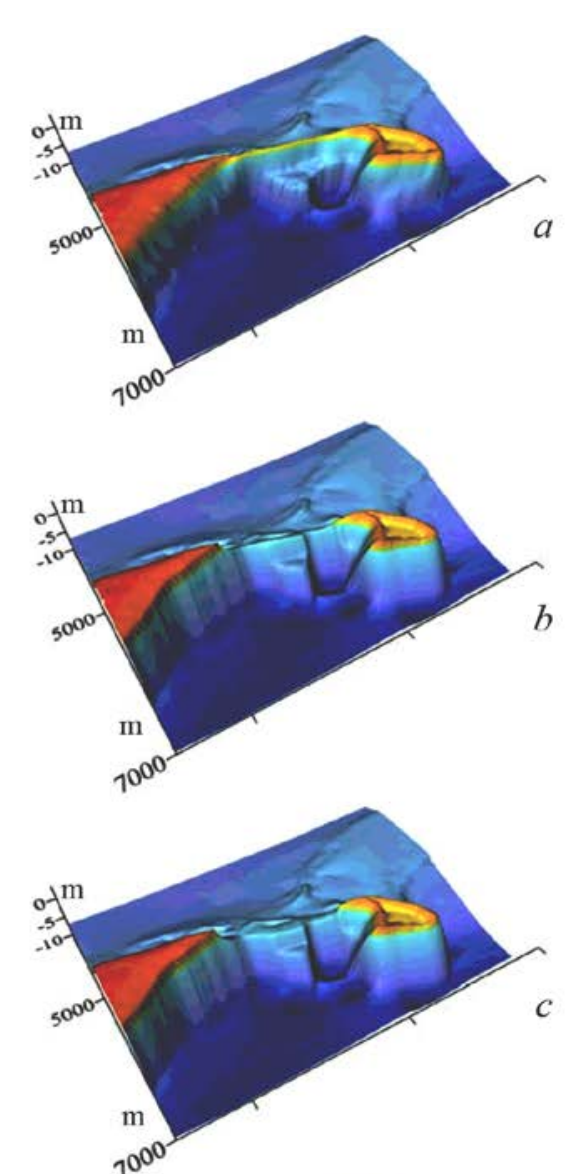
and seabed features. Besides, wave transformation near the coast is affected by local hydrodynamic processes such surges, which can lead to sufficient increase of dynamic depth. For example, in the apex of Karkinitsky Bay storm surges can reach $4 \mathrm{~m}$ height [8]. Therefore, we are to study the effect of wind wave direction and intensity and storm surge magnitude on the process of Bakalskaya Spit erosion.

At first let's consider a sediment transport in case of the storm wave running from the south-west, west and north-west in the absence of storm surges. At the northern, eastern and southern boundaries of computational domain the free passage conditions for the waves were specified. At the western boundary the incoming wave parameters were determined on the basis of (10), (11) relations. So far as the XBeach model is applied for the small coastal zone regions, the model does not take into account a spatial variability of wave spectrum specified at the western boundary. JONSWAP frequency spectrum parameters in the numerical experiments were

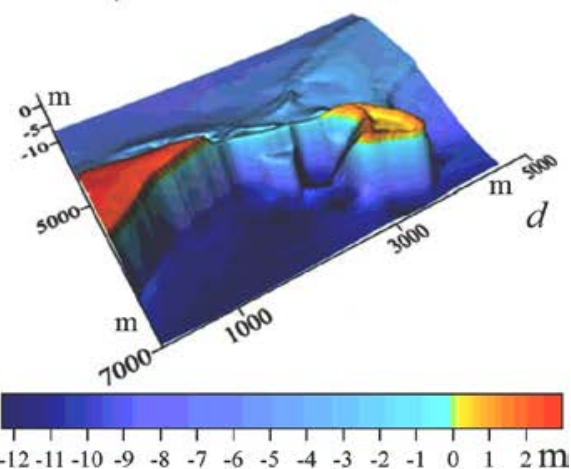
considered as the following: significant wave height $h_{s}=4 \mathrm{~m}$; wave peak period $\tau_{p}=6 \mathrm{~s}$; spectral peakedness $\gamma=3.3$; index of angular wave dissipation $l=10$. These parameters correspond to the developed storm wind waves and are obtained from the preliminary numerical experiments using spectral wave model SWAN (Simulating Waves Near Shore) [9].

Fig. 2. Bakalskaya Spit profile prior to the effect of waves and currents $(a)$ and after 24 hours of wave running from the south-west $(b)$, west $(c)$ and north-west $(d)$ 
The directions of steady wave currents (in 10 hours after the start of wind wave effect) generally correspond to the directions of running waves in all considered cases. Local features are manifested in the field of wave current velocities near Bakalskaya Spit and above Bakalskaya Bank. Thus, when waves run from the south-west in the narrow band along the spit western coast an increase of current velocities takes place, and when waves run from the north-west at the northernmost tip of the spit a cyclonic eddy is observed. Above Bakalskaya Bank the wave currents in these cases are directed almost meridionally.

An erosion of isthmus between the distal part of the spit and its main part and the occurrence of scour are observed at all considered wave directions (Fig. 2, $a-$ d). This process occurs most intensively when the waves run from the west (Fig. 2, c). In 4 hours a spit segment in the isthmus area appeared to be flooded, and after 24 hours the depths in this place reach $2-3 \mathrm{~m}$ (Fig. 3, c). In case of wave running from the south-west and north-west the isthmus appeared to be eroded in 8 hours and in 24 hours it appeared to be flooded at $1-2 \mathrm{~m}$ depths (Fig. 3, a, e). In all considering cases in the formed scour zonal component of wave current increases. Besides, in case of the wave running from the west a local intensification of wave currents in the scour takes place.

In the considering cases of wave running erosion occurs along the entire Bakalskaya Spit coastal zone (Fig. 3, $b, d$, $f$ ). The intensity of this process reaches its maximum along the west coast in the isthmus area, near the north-east segment of the head and also near the eastern shore, southward and northward of the scour occurred at the site of isthmus. When the waves run from the west the erosion areas directly in the isthmus region are the most extensive both in the zonal and meridional directions (Fig 3, d). In case of wave running from the south-west erosion occurs at depths which are slightly greater than in case of wave running from the north-west (Fig. 3, $b$, f).

The sediment accumulation on the seabed occurs seawards of erosion areas in a close proximity to them (Fig. 3, $b, d$, f). However, it doesn't take place along the entire Bakalskaya Spit coastline. So, when the waves run from the west there is practically no accumulation zone occurrence west of the isthmus. In all considering cases the most significant sediment accumulation takes place to the east of the spit head and south-east to the scour along the eastern coast of the spit. An accumulation zone westward from the spit appears to be the most significant in case of wave running from the south-west, and eastward from the spit - in case of wave running from the west (Fig. $3, b, d$ ). In the latter case the amount of accumulated sediments eastward from the spit also appears to be the most significant.

Now let us consider morphodynamic processes in the presence of storm surges. The calculations were carried out for four constant in time values of surges: 0.25; 0.50; 0.75; $1.00 \mathrm{~m}$. Whereas the height of Bakalskaya Spit isthmus in the applied digital relief doesn't exceed $0.6-0.7 \mathrm{~m}$, it was completely flooded at surges with 0.75 and $1.00 \mathrm{~m}$ values. 

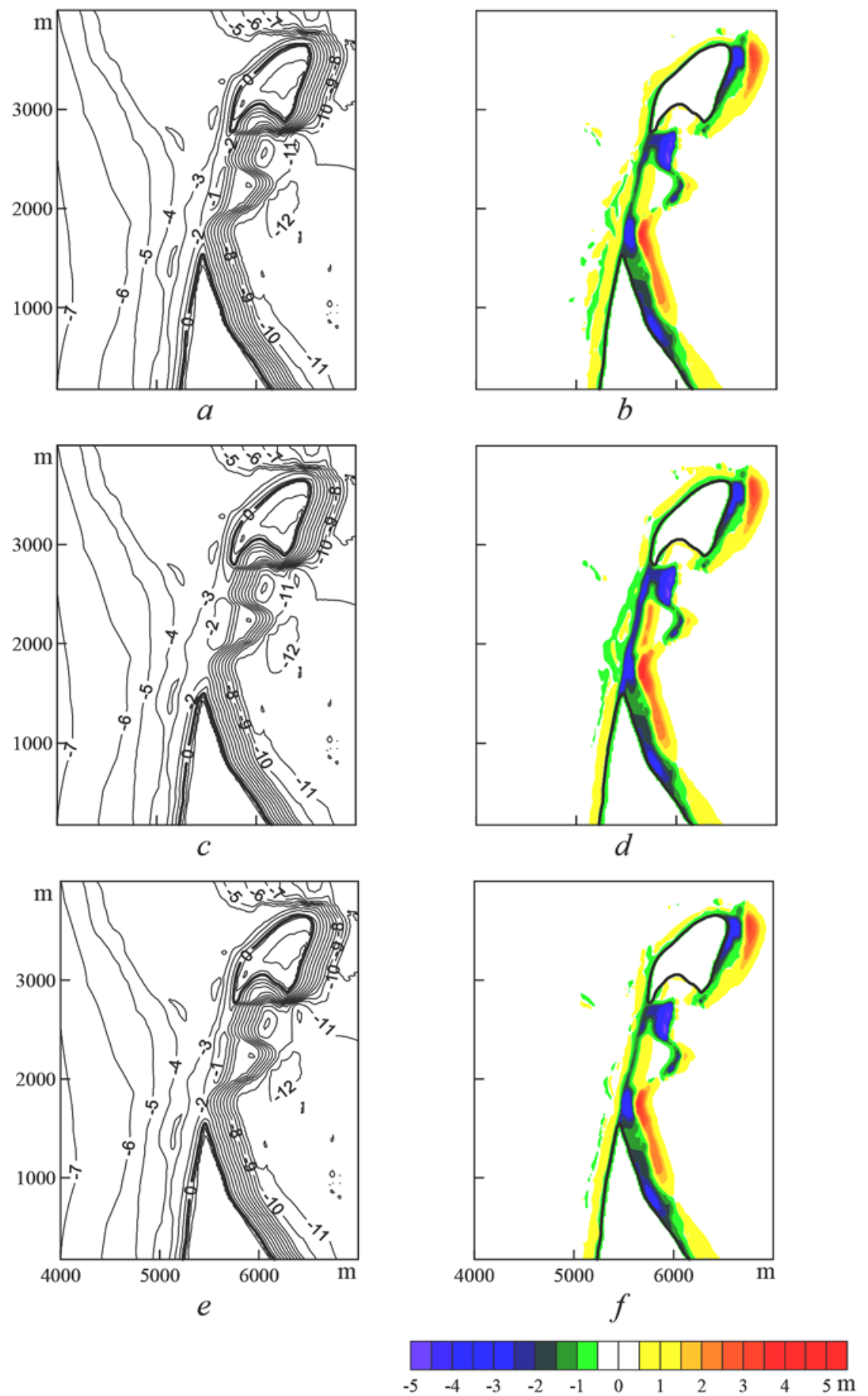

Fig. 3. Land and seabed relief (m) in Bakalskaya Spit region after 24 hours of $4 \mathrm{~m}$ height wave running from the south-west $(a)$, west $(c)$ and north-west $(e)$ and also the corresponding relief changes $(b, d, f)$ 

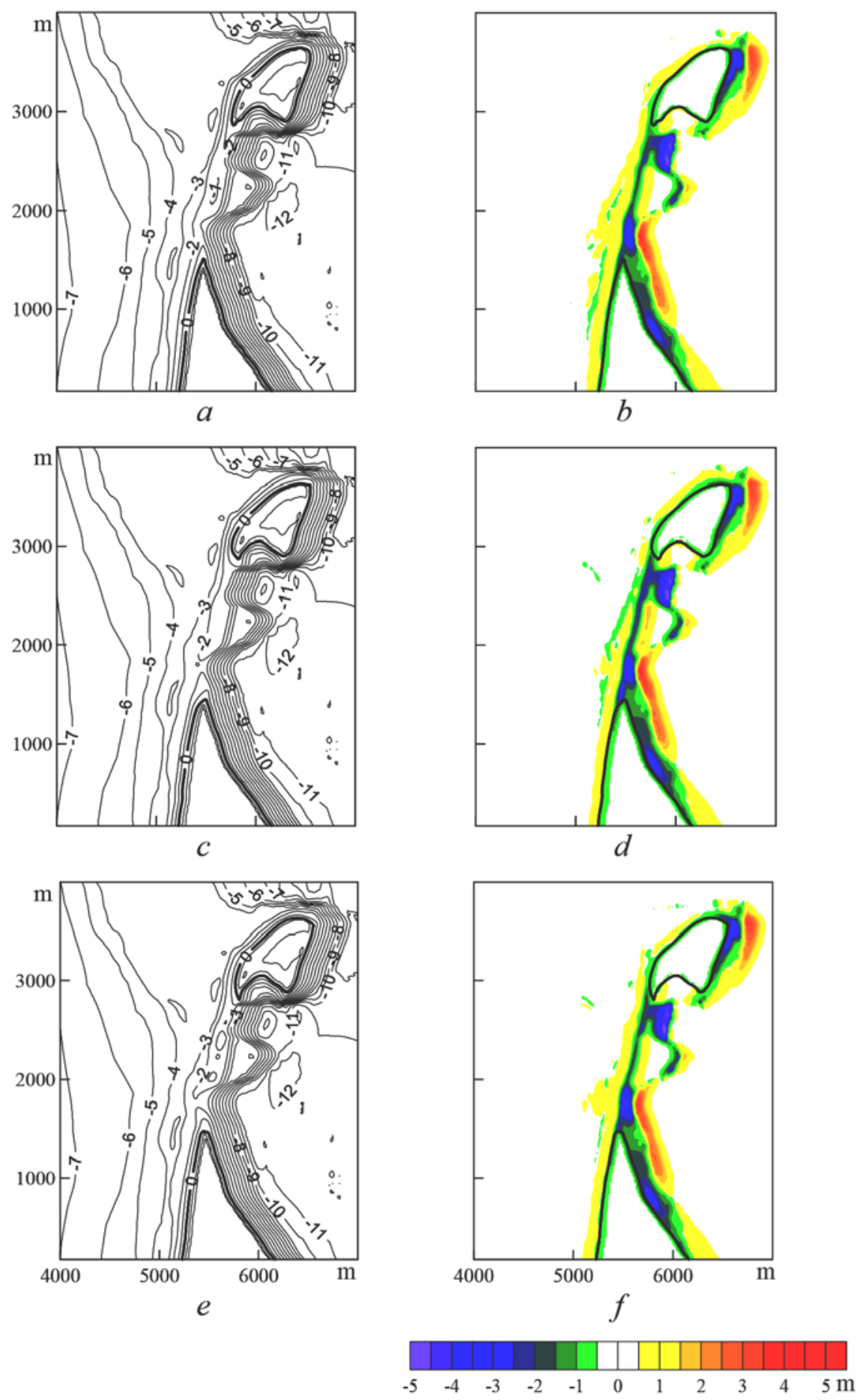

Fig. 4. Land and seabed relief (m) in the Bakalskaya Spit region after 24 hrs of $4 \mathrm{~m}$ waves running from the south-west $(a)$, west $(c)$ and north-west $(e)$ and corresponding relief changes $(b, d, f)$ in the presence of surge with $0.75 \mathrm{~m}$ height 

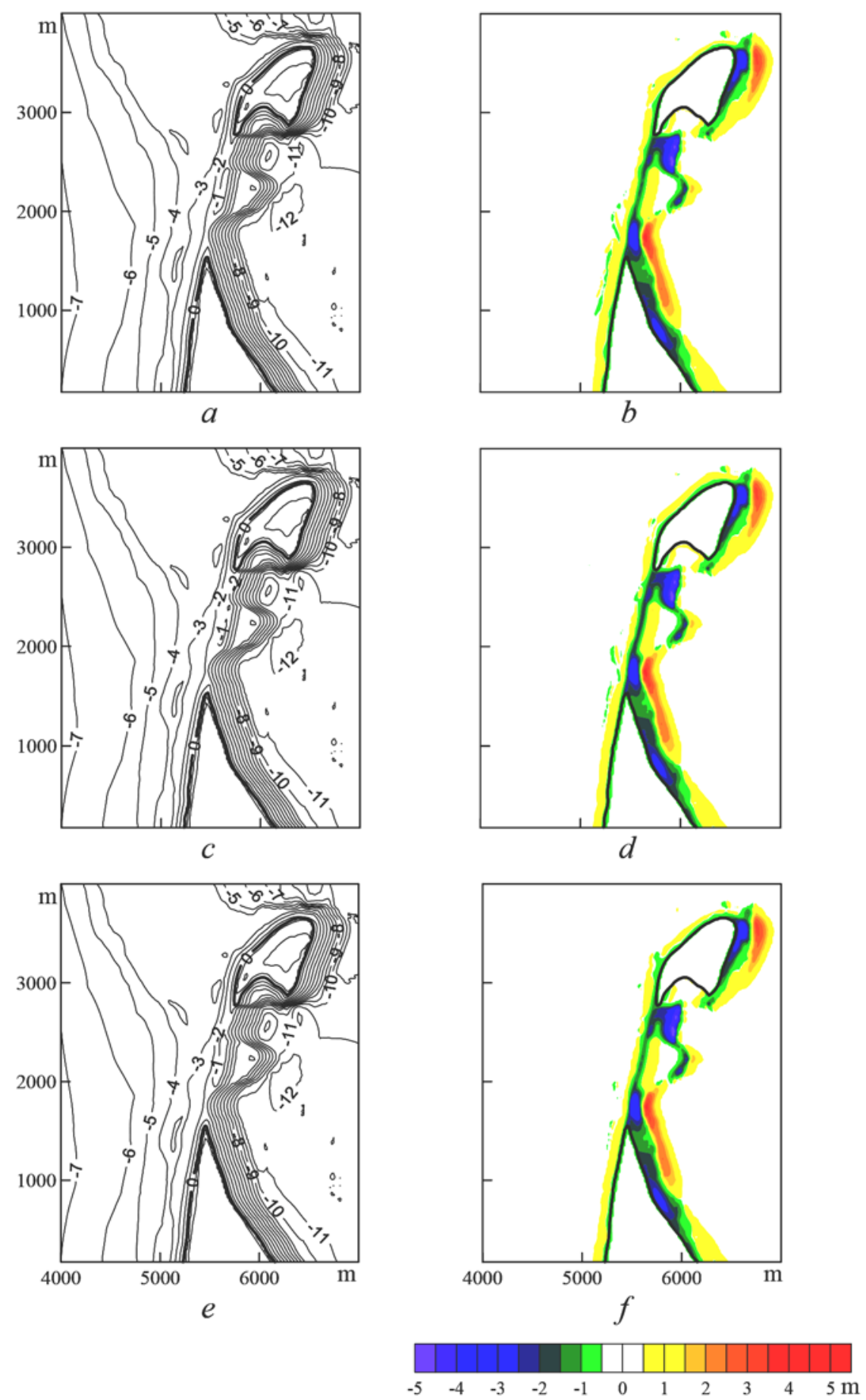

Fig. 5. Land and seabed relief (m) in the Bakalskaya Spit region after 24 hrs of $2 \mathrm{~m}$ waves running from the south-west $(a)$, west $(c)$ and north-west $(e)$ and corresponding relief changes $(b, d, f)$

The spatial structure of steady wave currents in the presence of surges largely remains the same as it was without them. Changes of erosion characteristics are PHYSICAL OCEANOGRAPHY NO. 1 (2015) 
manifested in the areas with depths up to $3 \mathrm{~m}$ in close proximity to Bakalskaya Spit and depend on the direction of wave running. Particularly, when the waves run from the south-west and north-west the intensity of erosion processes in the isthmus area increase with the growth of surge height (Fig. $4 a, e$ ). At the same time the difference in intensity and spatial localization of erosion becomes noticeable in these two cases. In case of wave running from the north-west the isthmus is eroded somewhat intensively than in case of wave running from the south-west. For example, in the first case after 24 hours at $0.75 \mathrm{~m}$ (height) surge the depth of erosion in certain isthmus areas reaches $3 \mathrm{~m}$ below the undisturbed sea level, and in the second case the same depth of erosion is reached at the surge with $1 \mathrm{~m}$ height. When integrating the model equations at longer time intervals these differences become noticeable at lower surge heights. In case of wave running from the west, on the contrary, the depth of isthmus erosion decreases with the increase of surge height (Fig. 4, c). Thus, after 24 hours the erosion up to $3 \mathrm{~m}$ below the undisturbed sea level at 0.25 $\mathrm{m}$ surge occurs in the north and the south of the isthmus except for its central part. At $0.50 \mathrm{~m}$ surge such magnitude of erosion is observed only in the south, closer to the main part of Bakalskaya Spit.

Thus, the obtained results are consistent with the conclusions made when carrying out the calculations at a coarse grid without taking into account the modern measurements of Bakalskaya Spit topography [10]. These conclusions are the following: in the presence of storm surges hydrodynamic processes, caused by wave running in direction range from western to the north-western, are most conducive to separation of Bakalskaya Spit head from its main part.

The presence of storm surges doesn't affect the localization of erosion areas along the Bakalskaya Spit shore, but it affects characteristics of sediment accumulation areas. This effect is the most significant along the western shore. With the increase of surge height, the accumulation areas extend seaward, exceeding the erosion areas by the width in several regions (Fig. $4, b, d$, f). The most extensive accumulation areas are formed at wave running from the south-west. In case of wave running from the west (after 24 hours and with the absence of surges) accumulation areas in the isthmus zone are insufficient, and in the presence of surges higher than $0.5 \mathrm{~m}$ they become sufficient and their areas exceed the ones of erosion zones.

Let us study the dependences of erosion process characteristics on wind wave intensity. For this purpose the waves with heights $h_{s}=3 ; 2 \mathrm{~m}$, running in the same directions as in previous numerical experiments with $h_{s}=4 \mathrm{~m}$ in the absence of storm surges are considered. The velocities of wave currents in the Bakalskaya Spit region sufficiently decrease at $2 \mathrm{~m}$ wave heights only. At the same time, spatial features of the Bakalskaya Spit isthmus erosion remain the same as in case of waves with $4 \mathrm{~m}$ height, and only the erosion depth decrease considerably. In case of wave running from the south-west and north-west it mainly makes up $1 \mathrm{~m}$ and only at the small areas it reaches $2 \mathrm{~m}$ (Fig. 5, a,e). At $3 \mathrm{~m}$ height of the wave running from the west the erosion areas with the depth up to $3 \mathrm{~m}$ still take place, but at $2 \mathrm{~m}$ wave height the erosion depth no longer exceeds $2 \mathrm{~m}$ below the sea undisturbed level (Fig. 5, c). The location of erosion and sediment accumulation areas generally corresponds to above-described case of $4 \mathrm{~m}$ wave running. But the differences resulting from the different wave running directions become practically insignificant at that (Fig. 5, $b, d$, $f$ ). It should be noted that the effects, caused by change of surge height, have a much greater effect on the morphodynamic 
processes than the change in the same relative proportion of significant wave height. Similar conclusions were obtained in [3], where the numerical experiments on the study of the XBeach model sensitivity to the input parameters are performed.

Conclusions. In conclusion we will briefly formulate the main results of study of morphodynamic process dependences in the Bakalskaya Spit region on the wind wave and storm surge parameters.

In all considered cases the XBeach model reproduces basic characteristics of the Bakalskaya Spit dynamics, obtained from the observational data analysis [2]. These characteristics could include: spit head displacement in the north-west direction due to erosion of its western part and sediment accumulation near its north-eastern part; spit erosion in the area of the isthmus, which connects the main part of the spit with its distal part up to its separation.

The most intensive erosion of the isthmus between the Bakalskaya Spit head and main part in the absence of surges occurs at wave running from the west. The wave running from the south-west and north-west causes erosion processes of almost equal intensity. Seabed erosion occurs along the entire coastline of the spit with different intensity. Sediment accumulation takes place seawards of erosion areas, but not continuously along the entire coast. The areas of most significant sediment accumulation are located to the east from spit head and to the south-west from the scour, along the eastern shore of the spit.

Storm surge effect on the morphodynamic process characteristics depends on the direction of wave running. In case of wave running from the south-west and northwest, seabed erosion intensity in the isthmus area increase with the surge height rising. At wave running from the north-west the isthmus erosion is somewhat more intensive than at wave running from the south-west. In case of wave running from the west, the increase of surge height results in the decrease of isthmus erosion depth. The presence of surges has no effect on the location of erosion areas. Sediment accumulation areas at that extend seawards.

Reduction of wind wave intensity results in decrease of distinctions of erosion area spatial distribution and sediment accumulation at different wave directions. Wave height change has a significantly lesser effect on process of Bakalskaya Spit erosion than the change of storm surge height.

Acknowledgements. The research was carried out under the support of the Project Developing of the methods and building experimental sample biotechnical monitoring system of the shelf zones of the seas of the Western Arctic and the South of Russia, including in the area of the Crimean peninsula, on the basis of satellite and contact data (code 2014-14-579-0115-020, RFMEFI60714X0059).

\section{REFERENCES}

1. Ivanov, V.A., Goriachkin, Yu.N. \& Udovik, V.F. [et al.], 2012, "Sovremennoe sostoyanie i ehvolyuciya Bakal'skoj kosy [Current state and evolution of the Bakalskaya Spit]", Ekologicheskaya bezopasnost' pribrezhnoy i shel'fovoy zon i kompleksnoe ispol'zovanie resursov shel'fa, vol. 1, no. 26, pp. 8-15 (in Russian). 
2. Goriachkin, Yu.N., Kharitonova, L.V. \& Dolotov, V.V., 2009, "Izmenchivost' beregovoy linii severo-zapadnogo Kryma [Changeability of the coastline of the North-West Crimea]", Ekologicheskaya bezopasnost' pribrezhnoy i shel'fovoy zon i kompleksnoe ispol'zovanie resursov shel'fa, no. 20, pp. 18-26 (in Russian).

3. McCall, R., 2008, "The longshore dimension in dune overwash modelling. Development, verification and validation of XBeach”, Thesis: Delft University of Technology, 147 p.

4. 2010, “XBeach model description and manual”, Unesco-IHE Institute for Water Education, Deltares and Delft University of Technology, 106 p.

5. Roelvink, D., Reniers, A. \& van Dongeren, A. [et al.], 2009, "Modeling storm impacts on beaches, dunes and barrier islands”, Coastal Engineering, vol. 56, pp. 1133-1152.

6. Blumberg A.F., 2002, “A primer for ECOMSED, Version 1.3.”, Mahwah, New Jersey: HydroQual, Inc., 188 p.

7. Blatov, A.S., Ivanov, V.A., 1992, “Gidrologiya i gidrodinamika shel'fovoy zony Chernogo morya”, Kiev, Naukova Dumka, 244 p. (in Russian).

8. Goriachkin, Yu.N., Ivanov, V.A., 2010, "Sovremennoe sostoyanie chernomorskikh beregov Kryma [Current state of the Crimea Black Sea coast]”, Dop. NAN Ukraini, no. 10, pp. 87-92 (in Russian).

9. http://www.swan.tudelft.nl.

10. Fomin, V.V., Alekseev, D.V. \& Kharitonova, L.V., 2013, "Modelirovanie morfodinamiki Bakal'skoy kosy [Modelling of the morfodynamic of the Bakalskaya Spit]", Ekologicheskaya bezopasnost' pribrezhnoy i shel'fovoy zon i kompleksnoe ispol'zovanie resursov shel'fa, no. 27, pp. 374-380 (in Russian). 